\title{
Prevalence and Associated Factors for Sick Leave Among Bulawayo City Health Employees, Zimbabwe, 2013
}

\author{
Cynthia Ncube $^{1 *}$, Chiedza Sibanda ${ }^{2}$ \\ ${ }^{1}$ Department of Community Medicine, University of Zimbabwe \\ ${ }^{2}$ City Health Department, Bulawayo City Council, Zimbabwe
}

\begin{abstract}
Sick leave is time spent away from work due to illness or injury. A preliminary review of sick leave records for 2012 for the 6 clinics in Nkulumane showed 3 clinics experienced higher sick leave incidents than the other 3 clinics. The study sought to establish the prevalence and associated factors for sick leave in the City of Bulawayo, Zimbabwe. An analytic cross-sectional study was carried out among Bulawayo City Health employees working in 20 health facilities. A total of 144 respondents and 3 key informants were interviewed. An interviewer-administered questionnaire, key informant interview guide, and a checklist were used to collect data, which was analysed using Epi Info. The prevalence of sick leave was 34\%. Employees who took sick leave less than six months ago were 4.3 times more likely to go on frequent sick leave than those who did not (POR 4.3, P-Value 0.002). Employees who reported good team climate were less likely to go on frequent sick leave (POR 0.29, P-Value 0.002). Feeling unappreciated at work was a risk factor for frequent sick leave (POR 2.61, P-Value 0.01). The cost of sick leave for the City of Bulawayo in 2012 was \$US20 840. Periodic refresher meetings on conditions of service, training of managers and other employees on good teamwork, and production of a standard template for recording sick leave by clinics may assist in curbing frequent sick leave incidents.
\end{abstract}

Keywords: Bulawayo, Prevalence, Sick Leave, Zimbabwe.

\section{Introduction}

Sick leave is the time that a person spends away from work because of illness or injury [1]. Absence from work because of sickness is disruptive and expensive. Although it is mostly attributable to ill health or injury, sick leave is also influenced by the personality of the worker, the physical and psychological demands of their jobs, social and cultural norms, and financial circumstances such as availability and levels of sick pay and social security benefits $[2,3,4]$. Sick leave is a necessary benefit for all employees [4]. Sick leave for staff has become a major problem for many organizations and industries worldwide in relation to costs [5].

To deal with challenges in the usage of sick leave, organizations and companies need to put several measures in place. These include being aware and responsive to subtle indications of worker unhappiness or tension, rewarding employees for zero absenteeism, educating new employees on about the conditions of service, with special emphasis on the usage of leave days, and training managers and supervisors so that they can deal perceptively and effectively with staff who have a lot of unexplained sick leave [6]. In Zimbabwe, the Labour Act Chapter 28:01 provides guidelines for sick leave for every employee. There is a provision for both paid and unpaid sick leave depending on one's circumstances [7].

In the City of Bulawayo, the usage of sick leave is guided by the conditions of service which are in line with the Labour Act of Zimbabwe. In addition, employees are required to submit a doctor's certificate if they exceed three days off sick. Clinics also have an 
additional requirement that even if an employee takes sick leave which is less than three days, they must fill in preliminary forms. The City of Bulawayo's conditions of service stipulates that if an employee applies for sick leave for more than three days, the employee must produce a letter from a doctor as proof of not being well. If the sick leave is three days long or less, no such proof is required. This means that employees can frequently abuse the sick leave facility if the leave does not exceed three days in one incident. It is of concern that a preliminary review of sick leave records for 2012 for the six clinics in the Nkulumane Division revealed that three clinics experienced higher incidents of sick leave compared to the other three clinics. Pelandaba experienced 120, Nkulumane 36, and Nketa 32 incidents. Of these incidents, high proportions (50\%, 69\%, and $78 \%$, respectively) were 3 days long or less. On the other hand, Maqhawe, Tshabalala, and Dr Shennan Clinics experienced very few incidents of sick leave, with an average of 7 incidents each. About $90 \%$ of the incidents in these clinics were more than 3 days long. Higher numbers of sick leave incidents are an indication that employees took sick leave repeatedly, regardless of the staff compliment. It was also noted that there is no standard way of recording sick leave in the clinics. The study was carried out to determine the prevalence and factors associated with sick leave in the City of Bulawayo.

\section{Methods}

An analytic cross-sectional study was carried out. Two groups of individuals were compared; those with frequent sick leave and those with infrequent sick leave. Frequent sick leave was defined as taking sick leave 3 times or more in 2012. Infrequent sick leave was defined as taking sick leave twice or less in 2012. Prolonged sick leave was defined as sick leave exceeding 2 weeks in total in 2012 [8]. A causeand-effect analysis using the Ishikawa Diagram [9] was done to identify all the possible causes of frequent sick leave. This is shown in Figure 1.

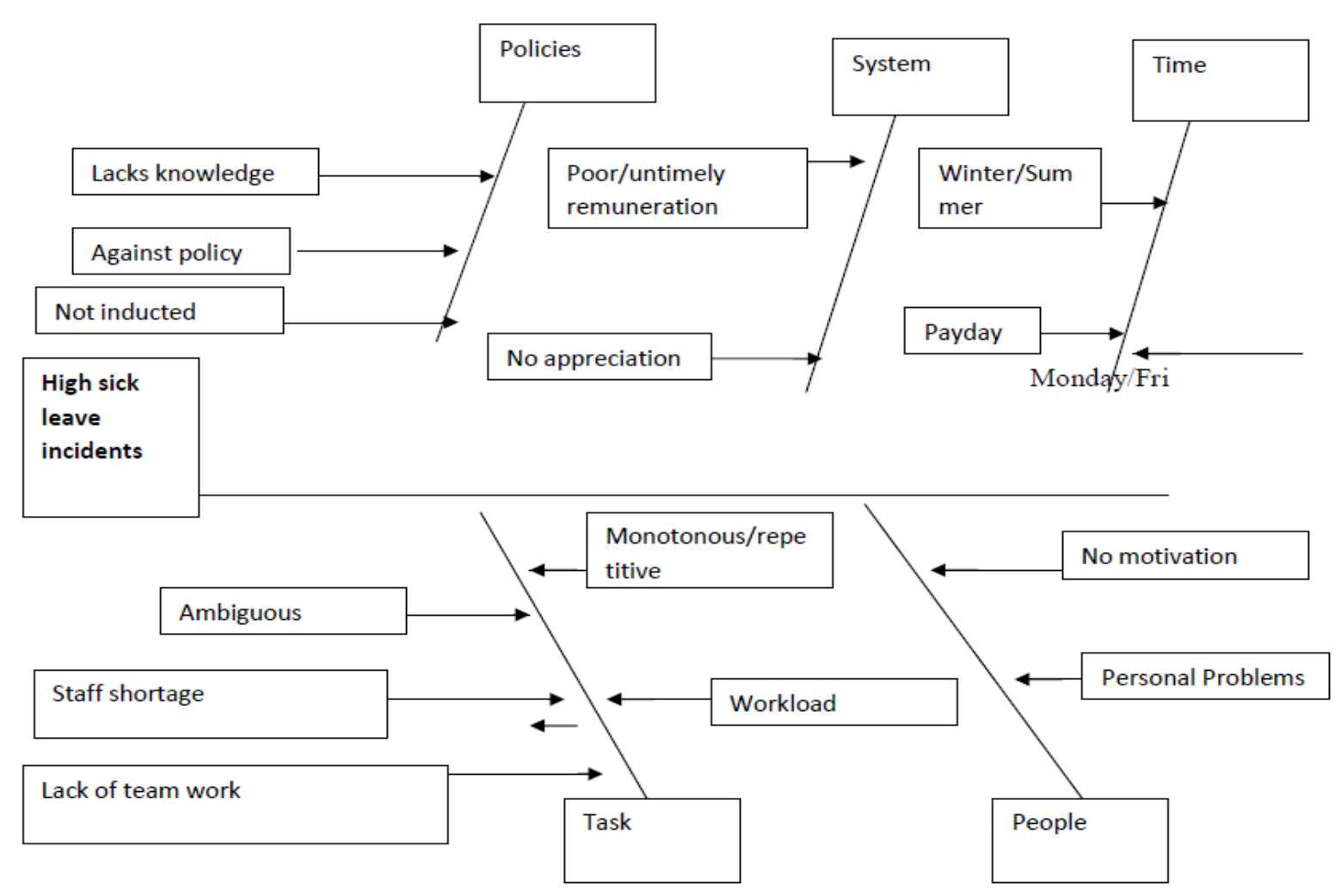

Figure 1. Cause and Effect Diagram, Sick Leave Incidents, City OF Bulawayo, 2013 
The Ishikawa Diagram was used to conceptualise the problem and was used in the development of the study tools.

The study population comprised of General Hands, Nurse Aides, Registered General Nurses, Community Health Sisters, and Sisters in Charge working in clinics in Bulawayo City clinics. The Staffing Officer and the Senior Administrative Officer were interviewed as key informants. All the twenty health facilities in the city were sampled into the study. 144 respondents and 3 key informants were interviewed. An interviewer-administered questionnaire, key informant interview guide, and a checklist to review leave records were used to collect data. Data were entered, cleaned, and analysed using Epi Info 7. Frequencies, Prevalence Odds ratios, and their $95 \%$ confidence intervals were generated. Univariate and bivariate analyses were done to check for associations between variables. Significant differences between respondents in terms of socio-demographic characteristics, educational status, and other factors were tested for using the Chi-square test. $P$ values less than 0.05 were considered statistically significant. Permission to conduct the study was sought from the City Health Director and the Health Studies Office.

\section{Results}

A total of 144 respondents were interviewed. The majority $(87.5 \%)$ of the respondents were female. Thirty-two percent (46) were registered general nurses, and forty-nine percent (70) were married. The median age of the respondents was 46 years, their median years in service 17 years whilst their median years in the current post was 7 years. Table 1 shows the demographic characteristics of respondents.

Table 1. Demographic Characteristics of Respondents, City of Bulawayo, 2013

\begin{tabular}{|l|l|}
\hline Variable & Frequency N=144 (\%) \\
\hline Sex & $18(12.5)$ \\
\hline Male & $126(87.5)$ \\
\hline Female & $46(37 ; 53)$ \\
\hline Median Age (Q1:Q3) \\
\hline Designation & $1(0.7)$ \\
\hline Boiler attendant & $10(6.9)$ \\
\hline Clerical assistant & $6(4.2)$ \\
\hline Community health sister & $1(0.7)$ \\
\hline Dental Therapist & $32(22.2)$ \\
\hline Cleaner & $1(0.7)$ \\
\hline Microscopist & $26(18.1)$ \\
\hline Nurse Aide & $1(0.7)$ \\
\hline Primary Care Counsellor & $46(31.9)$ \\
\hline Registered General Nurse & $10(6.9)$ \\
\hline State Certified Nurse & $10(6.9)$ \\
\hline Sister in Charge & \\
\hline Marital Status & $38(26.4)$ \\
\hline Single & $70(48.6)$ \\
\hline Married & $11(7.6)$ \\
\hline Separated & $5(3.5)$ \\
\hline Divorced & $20(13.9)$ \\
\hline Widowed & $17(8 ; 25)$ \\
\hline Median Years in Service (Q1; Q3) & \\
\hline
\end{tabular}


Most of the clients knew the definition of sick leave and the documentation required when one takes sick leave. However, only a small proportion $(31.3 \%)$ knew what happens when an employee exhausts the number of days they are entitled to in a year.

A set of six knowledge questions were used to score knowledge where 0-2 correct responses meant poor knowledge, 3-4 correct responses meant average knowledge, and 5-6 correct responses represented good knowledge on sick leave. Most $(65.3 \%)$ of the respondents with frequent sick leave had average knowledge on sick leave whilst most (54.7\%) of respondents with infrequent sick leave had average knowledge, as shown. The mean knowledge scores for respondents with frequent sick leave were 4.04 (SD 0.81), and the mean knowledge score for respondents with infrequent sick leave were 4.06 ( $S D$ 0.95). The difference in knowledge levels between the two groups was not statistically significant, as shown by a pvalue $>0.05$. Table 2 shows the knowledge score on sick leave for respondents.

Table 2. Knowledge Score on Sick Leave, City of Bulawayo, 2013

\begin{tabular}{|l|l|l|l|}
\hline \multirow{2}{*}{ Knowledge Score } & Frequent Sick Leave & Infrequent Sick Leave & \multirow{2}{*}{ P-Value } \\
\cline { 2 - 3 } & $\mathrm{N}=49(\%)$ & $\mathrm{N}=95(\%)$ & \\
\hline Poor Knowledge & $2(4.1)$ & $4(4.2)$ & \multirow{2}{*}{0.257} \\
\hline Average Knowledge & $32(65.3)$ & $52(54.7)$ & \\
\hline Good Knowledge & $15(30.6)$ & $39(41.1)$ & \\
\hline
\end{tabular}

On bivariate analysis, none of the sociodemographic factors were significantly associated with sick leave. On health service factors related to sick leave, having been inducted on council conditions of service and having access to the conditions of service document were protective factors against frequent sick leave. However, both factors were not statistically significant. Being happy with the workload, feeling appreciated at work, and the team climate in the health facility were significantly associated with sick leave. Employees who took sick leave less than six months ago were 4.3 times more likely to go on frequent sick leave than those who did not (POR 4.3, P-Value 0.002). Employees who reported a good team climate were less likely to go on frequent sick leave (POR 0.29, P-Value 0.002). Feeling unappreciated at work was a risk factor for frequent sick leave (POR 2.61, P-Value $0.01)$. The factors associated with sick leave are shown in Table 3.

Table 3. Factors Associated with Sick Leave, City of Bulawayo, 2013

\begin{tabular}{|l|l|l|l|l|}
\hline Factor & $\begin{array}{l}\text { Frequent Sick Leave } \\
\text { N=49(\%) }\end{array}$ & $\begin{array}{l}\text { Infrequent Sick Leave } \\
\text { N=95(\%) }\end{array}$ & POR & P-Value \\
\hline Took sick leave in past 2 years & $41(45.6)$ & & \\
\hline Yes & $49(59.4)$ & $54(100)$ & - & $<0.001^{*}$ \\
\hline No & $0(0)$ & $16(30.8)$ & 4.3 & $0.002^{*}$ \\
\hline Took sick leave <6 months ago & & \\
\hline Yes & $36(69.2)$ & $25(65.8)$ & 0.29 & $0.002^{*}$ \\
\hline No & $13(34.2)$ & & \\
\hline Team Climate & $18(45)$ & & \\
\hline Poor & $22(55)$ & $77(74)$ & 2.61 & $0.01^{*}$ \\
\hline Good & $27(26)$ & $71(73.2)$ & \\
\hline Felt Appreciated at work & 26(2.8) & \\
\hline Yes &
\end{tabular}




\begin{tabular}{|c|c|c|c|c|}
\hline No & $23(48.9)$ & $24(51.1)$ & & \\
\hline \multicolumn{5}{|c|}{ Happy with workload } \\
\hline Yes & $6(19.4)$ & $25(80.6)$ & 2.6 & $0.05 *$ \\
\hline No & $46(38.1)$ & $70(61.9)$ & & \\
\hline
\end{tabular}

On multivariate analysis, feeling appreciated at work and having a good team climate at work were both independent protective factors against sick leave. Having taken sick leave less than six months ago was an independent risk factor for sick leave. The independent factors associated with sick leave are shown in Table 4.

Table 4. Independent Factors Associated with Sick Leave, City of Bulawayo, 2013

\begin{tabular}{|l|l|l|l|}
\hline Variables & Adjusted OR & 95\% CI & P -Value \\
\hline Feeling appreciated at work & 0.3 & $0.1-0.9$ & $0.028^{*}$ \\
\hline $\begin{array}{l}\text { Having taken sick leave less } \\
\text { than 6 months ago, }\end{array}$ & 5.6 & $2.0-15.3$ & $0.0008^{*}$ \\
\hline Good Team Climate & 0.31 & $0.1-0.93$ & $0.038^{*}$ \\
\hline
\end{tabular}

The cost of sick leave for all the respondents was also calculated basing on the number of days each respondent took for sick leave in 2012. The calculated total cost of sick leave for 2012 was
\$US 20 840.This is shown in Table 5. There was no standard way of recording sick leave in the clinics.

Table 5. Cost of Sick Leave, City of Bulawayo, 2013

\begin{tabular}{|l|l|l|l|}
\hline Designation & $\begin{array}{l}\text { Total Number of Leave } \\
\text { Days Taken in 2012 }\end{array}$ & $\begin{array}{l}\text { Equivalent Salary } \\
\text { for one day (\$) US }\end{array}$ & $\begin{array}{l}\text { Cost of Sick } \\
\text { Leave (\$) US }\end{array}$ \\
\hline RGN (36) & 258 & 50 & 12900 \\
\hline Cleaner (17) & 155 & 8.3 & 1286.5 \\
\hline PCC (3) & 7 & 23.3 & 163.1 \\
\hline CA (3) & 20 & 23.3 & 466 \\
\hline SCN (8) & 55 & 40 & 2200 \\
\hline Nurse Aide (9) & 63 & 15 & 945 \\
\hline SIC (4) & 43 & 60 & 2580 \\
\hline CHS (1) & 5 & 60 & 300 \\
\hline TOTAL (81) & 606 & & 20840.6 \\
\hline
\end{tabular}

\section{Discussion}

Most of the employees who took sick leave in 2012 were female. This is because most health workers in the City of Bulawayo are female. In addition, according to literature, the majority of sick leave is pregnancy related and this might explain why females take leave more than males $[10,11]$. The highest proportion of employees who took sick leave were registered general nurses, followed by general hands. This could be linked to nurses complaining that their workload was too much and that their work was not being appreciated by some of their superiors. On the other hand, general hands seemed generally unhappy as most reported that fellow employees in higher grades look down on them due to their low grade and the nature of their work. In addition, general hands felt that their salaries are way too little compared to the amount of work that they do daily. This is supported by studies 
which showed that certain work characteristics and environments affect sick leave incidence $[12,13]$.

None of the socio demographic factors were associated with sick leave in this study. This is in contrast with Donders et al who found out that being female was associated with taking sick leave [6]. The reason why this factor was not significant in this study may be that most the respondents were female and hence comparisons by sex were not possible. This was not the case in the study by Donders, where almost equal proportions of both sexes were available for comparison. In a study, absence rate from work increased by age, gender, within migrant populations and single people [14].

Most employees knew the definition of sick leave and the documentation required when one takes sick leave. This is in line with the information obtained from the senior administrative officer who was interviewed as a key informant, that all employees are inducted on council conditions of service, including sick leave at the time of employment. However, most employees were not conversant with what happens when the number of sick leave days they are entitled to per year are exhausted. Since every section on sick leave is covered during the induction, this points out that employees need to be continually reminded of the conditions of service as they tend to forget with time. Overall, there was no significant difference in sick leave knowledge for employees with frequent sick leave and those with infrequent sick leave, owing to the induction, which caters to every employee.

Having a history of taking sick leave was an independent risk factor for frequent sick leave. This finding is consistent with [15] who found out that employees who were more likely to have an above-average sickness absence could be identified from their history of sickness absence in the past 2 years. This could be because when employees get comfortable with taking frequent sick leave, it is hard for them to stop once they have established that habit. The study [16] also further affirmed that short-term sick leave might have consequences for future sick leave beyond the effects of ill health. Per this study, it is important to pay attention to short-term sick leave to reduce future sickness absences. Study by [17] found out that long term sick leave associated with long term COVID-19 in Germany was very rare compared to short term sick leave.

A good team climate at work was protective against frequent sick leave in this study. When the team climate is good, there is a general feeling of being a family which supports each other always. Thus, a good team climate causes all employees to feel appreciated and that whatever contribution they are making, however small, is of great value. When team climate is poor, employees work as individuals or separate departments, which makes work more, harder and slower, leading to frustration and burnout. The finding is consistent with $[12,13,18]$ who found out that good team climate was associated with a decrease in the risk of sickness absence. Encouraging good teamwork may contribute to reducing sick leave in the city.

The third independent factor associated with sick leave was appreciation at work. Similar findings were made by [19], who reported that appreciation at work was associated with a decrease in the risk of sickness absence. When employees are appreciated, they become eager to do more without complaining a lot. Appreciating employees boosts their confidence in themselves, resulting in better outputs. When employees feel unappreciated, they tend to feel helpless and useless. This contributes to employees resorting to taking sick leave to be away from the depressing work environment. In this study, the greatest lack of appreciation was cited among general hands, and these need to be rectified.

It is worth mentioning that there are measures in place to prevent abuse of sick leave by employees. Firstly, staff members suspected of abusing sick leave may be asked to produce a doctor's certificate even within 3 days. If they 
continue, they may be asked to appear before a medical board to assess whether they are fit enough to continue with their duties or not. The cost of sick leave for the respondents amounted to more than US\$20 000. Considering that this was just a sample, the city could be losing millions of dollars through sick leave. It is therefore important for the city to continue monitoring sick leave amongst employees to prevent loss of money that could be used for other essential services. The city could benefit from studies that pointed out that it is important to have monitoring systems in place as reported sick leave becomes more imprecise as the number of days increases. In addition, the studies pointed out that to measure sick leave, data from company records is more accurate than self-reported sick leave data $[20,21]$.

\section{Conclusion}

The prevalence of sick leave among the respondents was 34\%. Socio-demographic factors were not associated with sick leave in this study. Having a history of sick leave less than six months ago was a risk factor for frequent sick leave. Team climate and appreciation at work were also associated with sick leave. There are measures in place in the city to prevent abuse of sick leave, and the cost of sick leave was more than US\$20000.

However, there was no standard way of recording sick leave in the clinics in the city.

\section{References}

[1] The Collins Online Dictionary: www.google.com accessed 17/07/2013.

[2] Coggon D; Ntani G; Vargas-Prada S; Martinez J.M; Serra C and Bernavides F.G, 2013, International Variation in Absence from Work Attributed to Musculoskeletal Illness: Findings from the CUPID Study: Occupational and Environmental Medical Journal, 70(8): 575-584

https://www.ncbi.nlm.nih.gov/pmc/articles/PMC371 0073/.
Periodic refresher meetings on conditions of service, including sick leave; training of managers on how to appreciate fellow employees, training employees on good teamwork and the production of a standard template for recording sick leave by clinics may assist in curbing frequent sick leave in the City.

\section{Conflict of Interests}

The authors declare no conflict of interest.

\section{Authors Contributions}

All authors were responsible for the conception of the problem, design, collection, analysis, and interpretation of data, and drafting of the final article. The manuscript was read and approved by all authors.

\section{Acknowledgements}

I would like to express my sincere gratitude to the University of Zimbabwe (UZ) department of community medicine academic and nonacademic staff for the support and guidance provided during this study. Special mention goes to my supervisors Mr. Notion Gombe, Chiedza Sibanda, and Dr. Hwalima, for their guidance. I also extend my gratitude to the Health Studies Office (HSO), Centres for Disease Control and Prevention (CDC), as well as City Health Department Employees.

[3] Brulin, C., Goine, H., Edlund, C. 1998, Prevalence of Long-Term Sick Leave Among Female Home Care Personnel in Northern Sweden. J Occup Rehabil 8, 103-111. https://doi.org/10.1023/A:1023063506148 https://link.springer.com/article/10.1023/A:1023063 506148\#citeas.

[4] Henrekson M and Mats Persson. 2004, The Effects on Sick Leave of Changes in the Sickness Insurance System. Journal of Labor Economics, 22 (8) 87-113. www.jstor.org/stable/10.1086/380404. 
[5] Smith M; Sick Leave Abuse, A Chronic Workplace Ill?

http://humanresources.about.com/od/laborrelations/a /sickleaveabuse.htm.

[6] Mindtools: Reducing Sick Leave: https://www.mindtools.com/pages/article/newTMM _56.htm.

[7] Law and Justice Zimbabwe: Labour Act of Zimbabwe:

http://www.mywage.org/zimbabwe/main/decentwork-check/work-and-illness/sick-leave.

[8] Donders N.C.G.M; Bos J.T; Van der Velden K and Van der Gulden J, 2012, Age Differences in the Associations between Sick Leave and Aspects of Health, Psychosocial Workload and Family Life, A Cross Sectional Study: BMJ Open: 2 (4), http://europepmc.org/article/PMC/4400637.

[9] Priya C, 2020: Ishikawa (Fishbone or Cause and Effect) Diagram:

http://learnersdestination.com/ishikawa-fishbone-orcause-and-effect-diagram/.

[10]Dørheim SK, Bjorvatn B, Eberhard-Gran M, 2013. Sick leave during pregnancy: a longitudinal study of rates and risk factors in a Norwegian population. BJOG.120(5):521-30. doi: 10.1111/1471-0528.12035. Epub 2012 Nov 7. PMID: 23130975.

https://pubmed.ncbi.nlm.nih.gov/23130975/.

[11] Backhausen M, Damm P, Bendix J, Tabor A, Hegaard H, 2017, The prevalence of sick leave: Reasons and associated predictors - A survey among employed pregnant women. Sexual \& Reproductive Healthcare.10.1016/j.srhc.2017.11.005.

https://www.researchgate.net/publication/321238369 _The_prevalence_of_sick_leave_Reasons_and_asso ciated_predictors_A_survey_among_employed_pre gnant_women.

[12] Rasmussen OB, Sørensen AU, Nielsen CV, 1996, Sick leave for pregnant women in the municipality of Fjend 1987-1990 Ugeskrift for Laeger.158(49):7069-7073. PMID: 8999614. https://europepmc.org/article/med/8999614.

[13] Holmgren, K., Dahlin-Ivanoff, S., Björkelund, C, 2009, The prevalence of work-related stress, and its association with self-perceived health and sickleave, in a population of employed Swedish women.
BMC Public Health 9, 73. https://doi.org/10.1186/1471-2458-9-73

https://bmcpublichealth.biomedcentral.com/articles/ 10.1186/1471-2458-9-73\#citeas.

[14]Fahlén, G., Goine, H., Edlund, C, 2009, Effortreward imbalance, "locked in" at work, and long-term sick leave. Int Arch Occup Environ Health 82, 191197. https://doi.org/10.1007/s00420-008-0321-5 https://link.springer.com/article/10.1007/s00420008-0321-5\#citeas.

[15] Isacsson A, Hanson BS, Janzon L, Kugelberg G, 1992, The epidemiology of sick leave in an urban population in Malmö, Sweden. Scandinavian Journal of Social Medicine ;20(4):234-239. doi:10.1177/140349489202000408

https://journals.sagepub.com/doi/abs/10.1177/14034 9489202000408.

[16]Roelen C.A; Koopmans P.C; Schreuder J.A; Anema J.R and Van Der Beek A.J, 2011: The history of registered sickness absence predicts future sickness absence, Journal of Occupational Medicine: 61(2):96-101 https://pubmed.ncbi.nlm.nih.gov/21173042/. [17]Jacob L, Koyanagi A, Smith L, Tanislav C, Konrad M, van der Beck S, Kostev K, 2021, Prevalence of, and factors associated with, long-term COVID-19 sick leave in working-age patients followed in general practices in Germany. Int J Infect Dis. 2021 Jul 2; 109:203-208. doi: 10.1016/j.ijid.2021.06.063. Epub ahead of print. PMID:34224870.

https://pubmed.ncbi.nlm.nih.gov/34224870/.

[18] Hultin H; Lindholm C; Malfert M and Moller J, 2012: Short Term Sick Leave and Future Rate of Sickness Absence and Unemployment: The Impact of Health Status: BMC Public Health: 12(861) https://bmcpublichealth.biomedcentral.com/articles/ 10.1186/1471-2458-12-861\#citeas.

[19]Hinnka K; Kuoppala J; Vaananen-Tomppo I and Lamminpaa A, 2013: Psychosocial work factors and sick leave, occupational accident, and disability pension; a cohort study of civil servants: Journal of Occupational and Environmental Medicine:55(2):191-7

https://pubmed.ncbi.nlm.nih.gov/23364212/. 
[20] Stapelfeldt, C.M., Jensen, C., Andersen, N.T, 2012, Validation of sick leave measures: selfreported sick leave and sickness benefit data from a Danish national register compared to multiple workplace-registered sick leave spells in a Danish municipality. BMC Public Health 12, 661. https://doi.org/10.1186/1471-2458-12-661 (Self https://link.springer.com/article/10.1186/1471-245812-661\#citeas.
[21] Van Poppel MN, de Vet HC, Koes BW, Smid T, Bouter LM, 2002, Measuring sick leave: a comparison of self-reported data on sick leave and data from company records. Occup Med (Lond);52(8):485-90. doi: 10.1093/occmed/52.8.485. PMID:12488520.

https://pubmed.ncbi.nlm.nih.gov/12488520/. 